\title{
Türkiye'nin “Elektrikli Makine ve Cihaz” Sektörünün Açıklanmış Karşılaştırmalı Üstünlükler Endeksi ile Analizi
}

\author{
Vildan Saba AKTOP ${ }^{1}$
}

$\ddot{O} z$

Bu çalışmanın amacı, 2000-2019 yılları arasında Türkiye'nin ISIC Rev. 331 kodlu "Başka yerde sınıflandırılmamış elektrikli makine ve cihazlar" sektörünün belli başlı sektörlerinin dünya karşısındaki rekabet gücünü "Açıklanmış Karşılaştırmalı Üstünlükler Endeksi” ile analiz etmektir. Etki alanı oldukça geniş olan bu sektör kolunun kapsamı da oldukça geniştir. Elektrik sektöründe üretilen sofistike ürünler diğer sektörler tarafindan yoğun bir şekilde kullanılmakta ve ekonomi içerisinde hızla yayılmaktadır. Bir sektörün tümünde bir ülkenin tek başına karşılaştırmalı üstünlüğe sahip olması mümkün değildir. Çünkü bu alandaki üretim büyük bütçeli yatırımları gerektirmektedir. Dolayısıla bir ülkenin hangi spesifik alt sektörlerde uzmanlaşmayı tercih edeceği ve bunlara nasıl destek sağlayacağının tespit edilmesi ülkenin kaynaklarının etkin bir biçimde değerlendirilmesi açısından son derece önemlidir. Çalışmanın sonucuna göre 2000-2019 yılları arasında "Elektrik motorları, jeneratörler ve transformatörlerin imalatı", "Elektrik dağıtım ve kontrol cihazları imalatı", "İzole tel ve kablo imalatı", "Akümülatör, birincil pil ve birincil pil imalatı", "Elektrikli ev aletleri ve beyaz eşya imalatı", "İzole tel ve kablo imalatı", "Elektrik lambaları ve aydınlatma teçhizatı imalatı” içerisinde rekabet gücüne sahip alt sektörler tespit edilmiştir.

Anabtar Kelimeler: Elektrikli Makine ve Cihaz İmalat Sektörü, Dış Tícaret, Uluslararası Rekabet Gücü, Rekabet Gücü Ölçümü, Açıklanmış Karşılaştırmalı Üstünlükler Endeksi

\section{Analysis of Turkey's “Electric Machinery and Equipment” Industry applying Revealed Comparative Advantage Index}

\section{Abstract}

The purpose of this study is to analyze Turkey's ISIC Rev. 3 31-coded "Electrical machinery and equipment not classified elsewhere" sector between 2000-2009 against world's competitors applying "Revealed Comparative Advantage Index". The scope of the electrical equipment-manufacturing branch, which has a wide area of influence, is also quite broad. Sophisticated products produced in the electricity sector are used extensively by other sectors and are spreading rapidly in the economy. It is impossible for a single country to have a comparative advantage in an entire sector due to the fact that production in this area requires large-budget investments. Therefore, determining which specific sub-sectors country will choose to specialize in and how it will support them is extremely important in terms of consuminh country's resources effectively. In this study, Competitive sectors are determined from "Manufacture of electric motors, generators and transformers", "Manufacture of electrical distribution and control devices", "Manufacture of insulated wires and cables", "Production of accumulators, primary batteries and manufacture of primary batteries", "Electrical home appliances", "Manufacture of insulated wire and cable", "Manufacture of electrical lamps and lighting equipment" sectors.

Key Words: Electric Machinery and Equipment Manufacturing Sector, International Trade, International Competitiveness, Competitive Power Measurement, Revealed Comparative Advantages Index.

\section{Atıf İçin / Please Cite As:}

Aktop, V. S. (2021). Türkiye'nin “elektrikli makine ve cihaz” sektörünün açıklanmış karşılaştırmalı üstünlükler endeksi ile analizi. Manas Sosyal Araştırmalar Dergisi, 10(2), 1083-1093.

Geliş Tarihi / Received Date: 05.05.2020

Kabul Tarihi / Accepted Date: 25.01.2021

\footnotetext{
1 Arş. Gör. Dr. - Türkiye-Afyon Kocatepe Üniversitesi İktisadi ve İdari Bilimler Fakültesi, saktop@aku.edu.tr

(iD ORCID: 0000-0002-5636-5290
} 


\section{Giriş}

Uluslararası rekabet gücünün elde edilmesi ve bunun sürdürülmesi, günümüz rekabet koşullarında oldukça önemlidir. Rekabet gücüne sahip olmak için birçok kriterin sağlanması gerekmektedir. Yeni teknolojilere uyum sağlayan, sermaye ve emeği verimli kullanan, ürün kalitesini geliştiren firmaların rekabet gücü hızla artmakta ve uzun vadede ise sürdürülebilir bir büyüme göstermektedir. Uluslararası rekabet gücüne sahip firmalar uluslararası değer değer zincirinin başarıla entegre olabilmekte ve bu şekilde piyasa meydana gelen değişikliklerine ve taleplere daha hızlı bir şekilde cevap verebilmektedir. Günümüzde rekabet gücü sağlamak ve bunu sürdürmek için firmalar teknoloji geliştirilmesi, Ar-Ge faaliyetleri sonucunda yeni ürünlerin piyasaya çıkması ve süreç yenilikleri yapılması için çaba sarf etmektedir. Yüksek standartlarda üretim yapan rekabetçi firmalar emek verimliliği yüksek, nitelikli personel istihdam etmekte firma performansı ve başarısı önemli ölçüde artmaktadır.

Standart ürünlerde üretim yapılması durumunda en düşük maliyetle üretim yapan ülkeler rekabet gücüne sahip olacaktır. Düşük maliyetle üretim yapan ülkeler karşısında rekabet üstünlüğüne sahip olmak oldukça güçleşmiştir. Bu nedenden dolayı firmaların rekabet gücü elde etmek için daha önce denenmemiş, farklı alanlarda faaliyet göstermeleri ya da faaliyetlerini farklılaştırmaları gerekmektedir. Ar-Ge faaliyetleri sonucunda ortaya çıkan süreç yenilikleri üretim maliyetlerinin azalmasına neden olmaktadır. Ürün kalitesinin gelişmesini sağlayan yenilikler ile birlikte yurtiçi ve yurtdışı piyasa payı artmaktadır. Yeni ürünlerin piyasaya çıkmasını ve yeniliği gerçekleştiren firma, belirli bir süre monopol gücü elde etmekte ve monopol kâr1 elde etmektedir.

Uluslararası rekabet gücüne sahip sektörlerin tespit edilmesi ve bu alanlara teşviklerin verilmesi, ticaret potansiyelinin yüksek olan alanların desteklenmesi ülkenin kaynaklarının doğru alanlara yönelmesi açısından önemlidir. Uluslararası rekabet gücünün ölçülmesi, bir sektörün dünya pazarındaki konumunun ortaya konulması açısından önemli bir göstergedir. Hiçbir ülkenin bir sektörün tümünde tek başına rekabet gücü avantajına sahip olması mümkün değildir. Bu nedenden dolayı ülkelerin küresel değer zincirine yüksek katma değerli üretim ile katılması önem kazanmaktadır. Bu çalışmada Türkiye'deki önemli sektörlerden birisi olan "Elektrikli Makine ve Cihaz" sektörünün "Açıklanmış Karşılaştırmalı Üstünlükler Endeksi”ne göre dünya piyasalarındaki rekabet gücüne sahip alt sektörlerinin tespit edilmesi amaçlamıştır.

"Elektrikli Makine ve Cihaz" sektörü, bir enerji kaynağı olan elektriği insanlar için yararlı hale dönüştürecek olan yüksek katma değerli ürünlerin üretilmesi sağlamaktadır. Sektör, geniş bir ürün grubuna sahip olup ara girdi, yatırım malı ve nihai tüketim malı üreterek elektrik enerjisi üretimi, dağıtımını yapan ve elektrik enerjisi kullanan ürünlerin üretimini gerçekleştirmektedir. Ürün grupları içerisinde elektrikli ev gereçleri, sinyalizasyon teçhizatı, elektrikli sinyalizasyon ve aydınlatma gereçleri yer almaktadır (ISO, 2014).

OECD tarafindan önerilen Ar-Ge yoğunluk (ISIC Rev. 4) sinıflandırmasında, teknoloji sinıflandırmasinda (ISIC Rev. 3) ve Eurostat teknoloji siniflandırmasinda (Nace Rev. 2) orta-yüksek teknolojili bir sektör olan "Başka yerde sınıflandırılmamış elektrikli makine ve cihazlar" sektörü, Türkiye'nin önemli sektörlerinden birisidir. İleri ve geri bağlantı katsayıları yüksektir ve Türkiye ekonomisi içerisinde kilit sektörlerden birisi konumundadır. Bunun anlamı diğer sektörlere yoğun bir şekilde girdi sağlamakta ve diğer sektörlerden yoğun bir biçimde girdi almaktadır. Endüstriler arası bağlantıları güçlüdür. Bu özelliklerinden dolayı ISIC Rev. 431 kodlu "Başka yerde sınıflandırılmamış elektrikli makine ve cihazlar" sektörünün alt sektörleri içerisinde uluslararası rekabet gücü açısından yüksek olan sektörlerin tespit edilmesi, bu alandaki yatırımların teşvik edilmesi ve bu sektörlere daha fazla Ar-Ge desteğinin verilmesi açısından bir gösterge olabilecektir.

\section{Türkiye’de “Elektrikli Makine ve Cihazlar” İmalatı Sektörü}

Uluslararası rekabet gücü açısından teknoloji altyapısı ve yeni teknoloji geliştirme yeteneği belirleyici nitelikte olmaktadır. Bu sektörde Japonya, Güney Kore, Tayvan, Singapur, Fransa, Almanya, Amerika Birleşik Devletleri, İsveç gibi ülkeler rekabet gücüne sahip ülkelerdir. Elektrikli küçük ev aletleri ve beyaz eşya sektöründe yenilikçilik ve ürün çeşitliliği artmakta ve bu sektörde yüksek düzeyde Ar-ge harcaması yapılmaktadır. Beyaz eşya sektörü kendi üretim teknolojisine büyük ölçüde sahiptir. Diğer alt sektörlerde dışa bağımlılık sürmektedir ve önemli ölçüde yabancı sermaye yatırımları söz konudur (İstanbul Ticaret Odas1, 2014). Türkiye, Gümrük Birliği ile yoğun bir dış rekabetle karşılaşmış ve Avrupa Birliği üyesi ülkelerle rekabet sonucunda ürün çeşitliliğini ve kalitesi artmıştır. Elektrikli ev aletleri sektöründe yeni tasarımlar ve teknolojiler geliştirerek bu sektörde teknoloji transfer eden bir ülke konumuna gelmiştir. Avrupa Birliği, üye ülkelerin ve Türkiye'nin piyasalara arz edecekleri ürünlerin CE (Conformite European) 
işareti bulunmasını zorunlu tutmaktadır. Bu anlamda CE işareti taşımak, Avrupa Birliğı’nin teknik mevzuata uyumunu sağlamaktadır (Türkiye Cumhuriyeti Ekonomi Bakanllğı İhracat Genel Müdürlüğü, 2016, s.2-3).

Tablo 1. Türkiye'nin ISIC Rev 3.31 Kodlu "Başka Yerde Simflanderlmamıs Elektrikli Makine ve Cibąlar" Sektörünün İhracat, İthalat Değerleri (Dolar Cinsinden) ve Toplam İhracat-Ithalat İgerisindeki Yüzde Paylar

\begin{tabular}{lccccc}
\hline Ürün Kodu (27) & İhracat & $\mathbf{\%}$ & İthalat & $\mathbf{\%}$ & D1ş Ticaret Dengesi \\
\hline $\mathbf{2 0 1 5}$ & 5.432 .543 .977 & 3,77 & 7.840 .303 .501 & 3,78 & -2.407 .759 .524 \\
$\mathbf{2 0 1 6}$ & 5.223 .275 .372 & 3,66 & 8.374 .314 .716 & 4,21 & -3.151 .039 .344 \\
$\mathbf{2 0 1 7}$ & 5.326 .214 .493 & 3,39 & 8.358 .627 .660 & 3,57 & -3.032 .413 .167 \\
$\mathbf{2 0 1 8}$ & 5.831 .525 .057 & 3,47 & 8.507 .789 .875 & 3,81 & -2.676 .264 .818 \\
$\mathbf{2 0 1 9}$ & 5.928 .553 .210 & 3,45 & 7.745 .510 .560 & 3,82 & -1.816 .957 .350 \\
$\mathbf{2 0 2 0}$ & 5.228 .179 .896 & 3,64 & 7.576 .515 .137 & 4.02 & -2.378 .335 .241 \\
\hline
\end{tabular}

Kaynak: TÜIK

Not: 2020 verileri geçicidir.

Tablo 1'e göre 31 kodlu sektör ticaret dengesi açığı vermektedir. Bu sektörde Türkiye ithalatçı bir ülke konumundadir.

Tablo 2. Türkiye'nin ISIC Rev. 331 Kodlu Sektörde En fąla İbracat ve İthalat Yaptrğ 5 Ülke (2019-Dolar Cinsinden)

\begin{tabular}{llll}
\hline İhracat Yapılan Ülke & İhracat Değeri & İthalat Yapılan Ülke & İthalat Değeri \\
\hline İngiltere & 572.664 .522 & Çin & 1.765 .298 .747 \\
Irak & 414.236 .096 & Almanya & 1.048 .296 .984 \\
Almanya & 412.350 .874 & Japonya & 566.145 .356 \\
Fransa & 322.191 .661 & Fransa & 450.406 .718 \\
Suudi Arabistan & 185.776 .453 & ABD & 386.833 .917 \\
\hline
\end{tabular}

Kaynak: TÜIK

Tablo 2'ye göre Türkiye ISIC Rev. 331 kodlu sektör ihracatını en fazla İngiltere’ye yapılmaktadır. İngiltere'yi Irak, Almanya, Fransa, Suudi Arabistan takip etmektedir. Türkiye'nin en fazla ithalat yaptı̆̆1 ülkeler ise Çin, Almanya, Japonya, Fransa ve ABD olmuştur.

\section{Uluslararası Rekabet Gücü ve Açıklanmış Karşılaştırmalı Üstünlükler Endeksi}

Uluslararası rekabet gücünü ve rekabetçiliği açıklamaya yönelik farklı görüşler vardır. Farklı kurumlar tarafindan farklı uluslararası rekabet ve rekabet gücü tanımlamaları yapılmıştır. Ulusal rekabet gücü, "bir ülkenin uluslararası ticarette ürün yaratma, üretme, dağıtma ve/veya sunma yeteneğidir" (Scott ve Lodge, 1985, s. 3). Ülkelerin ekonomik büyüme, istihdam yaratma, ödemeler dengesizliğini ortadan kaldırma gibi temel iktisat politika hedeflerini gerçekleştirme yeteneğidir (Fagerberg, 1988, s. 355). Bir ülkenin hedeflediği faktör gelirleriyle ve tatminkâr bir makro ekonomik ortamda dünya piyasalarına yeterli ürün ve hizmet satabilme yeteneğidir. Bu yetenek, fiziki ve beşeri sermaye, teknoloji gibi ülkedeki iç kaynaklara bağlı görülmektedir (Aiginger, 1998, s. 164).

Michael Porter (1990), "Uluslarn Rekabet Avantaj1 (Competitive Advantage of Nations)" adlı çalışmasında rekabet gücünün unsurlarını uluslararası düzeyde araştırmıştır. Rekabetçilik, bir ülkenin ekonomik açıdan benzer düzeydeki ülkelerle kıyaslandığında uluslararası piyasalardaki konumunu göstermektedir. Bir ülkenin uluslararası piyasalarda bulunduğu konum, ülkelerin bilgi-teknoloji altyapıları, eğitim-öğretim, siyasi ve ekonomik istikrar, iletişim ve sağlık, kamu kurumlarının yeterliliğini içermektedir. Bu unsurlar firmaların hayatta kalması ve rekabet avantajı sağlaması açısından oldukça önemlidir.

OECD, rekabet gücünü serbest ticaret ve adil piyasa koşulları altında bir ülkenin uluslararası piyasa koşullarına uygun mal ve hizmet üretebilmesi ve aynı zamanda vatandaşlarının uzun dönemde reel gelirlerini artırmaya odaklanabilmesi olarak tanımlamaktadır (Walsh, 1994, s. 237). Rekabetçilik, ulusların işletmeler için rekabet edebilecekleri bir ortamı yaratma ve sürdürme, nüfusunun refahını artırmak için kaynaklarının ve yeterliliklerinin bütünlüğünü yönetme yeteneğidir (IMD, 2003).

Rekabetçi olabilmek için araştırma ve geliştirme, yenilikçilik, bilgi ve iletişim teknolojileri, girişimcilik, rekabet, eğitim ve öğretim açısından rakiplerinden daha iyi performans gösterilmesi gerekmektedir (European Commission, 2003). Uluslararası rekabetçilik kavramı oldukça karmaşık bir kavram olmakla birlikte genel anlamda rekabet edebilirlik, bir ülkenin uluslararası ticarette avantajlı konumda olması ve bu 
konumunu zamanla iyileştirme kabiliyetinin olması anlamına gelmektedir. Bir ülke reel ücret artı̧ı sağlayan yüksek bir büyüme oranına sahip ise uluslararası piyasalarda yerli firmalarını destekleyerek yeni iş alanları yaratmaları için yardımcı olabilecektir. Bu koşullar altında o ülkenin rekabetçi bir konuma sahip olduğu söylenebilir (Rusu ve Roman, 2018, s. 2045).

Farklı tanım ve görüşlerden yola çıkılarak uluslararası rekabet gücünün üç özelliği olduğu söylenebilir. Birincisi, uluslararası rekabet gücü sağlamanın temel amacı refah artı̧ı ve yaşam standardının artırılmasıdır. İkincisi ülkeler kendilerine özgü yeteneklerine odaklanarak rakip ülkeleri ürün üretimi ve dağitımında yakalayabilmektedir. Üçüncüsü bir ülkenin rekabet edebilme gücünün tespit edilmesinde üretim, istihdam, dış ticaret bilançosu, uluslararası piyasalardaki pazar payı gibi birçok gösterge bir arada kullanılmalıdır (Çivi, Erol, İnanlı ve Erol, 2008, s. 4).

Uluslararası rekabet gücünü ölçmeye yönelik farklı endeksler geliştirilmiştir. Bu endekslerden birisi de literatürde sıklıkla kullanılan "Balassa Endeksi”dir. Bela Balassa (1965), ülkelerin ihracat verileri ile ölçtüğü karşılaştırmalı üstünlüğe "Açıklanmış Karşılaştırmalı Üstünlükler" olarak adlandırmıştır. "Balassa Endeksi”" ile karşılaştırmalı olarak zayıf ve güçlü olan ihracat sektörlerinin belirlenmesi amaçlanmaktadır (Hinloopen ve Marrewijk, 2004, s. 1). Aşağıda “Açıklanmış Karşılaştırmalı Üstünlükler (AKÜ) Endeksi”nin formülü yer almaktadir.

$$
A K \ddot{U}=\left(\frac{(X i j / X i t)}{(X n j / X n t)}\right)
$$

1 nolu endeks formülündeki $X_{\mathrm{ij}}$, $\mathrm{i}$ ülkesinin “j” sektör ihracatt; $\mathrm{X}_{\mathrm{it}}$, i ülkesinin toplam ihracat1, $\mathrm{X}_{\mathrm{nj}}$; Dünya'nın “’”” sektör ihracat1, $X_{n t}$, Dünya'nın toplam ihracatını göstermektedir. AKÜ endeksinin 1'den büyük olması durumunda ülkenin ilgili sektörde dünyaya karşı rekabet gücünün olduğunu, 1'den küçük olması durumunda dünyaya karşı rekabet dezavantajına sahip olduğu söylenebilir.

\section{Literatür Taraması}

Sektörlerin uluslararası rekabet gücünü ölçemeye yönelik literatürde birçok çalışma yapılmışıtır. Uluslararası rekabet gücünün ölçülmesine çoğunlukla "Açıklanmış Karşılaştırmalı Üstünlükler endeksi kullanılmıştır”. Bir ülkenin diğer ülke veya ülke grupları karşısındaki karşılaştırmalı üstünlüklerini belirlemesi konusundaki ilk çalışma Liesner (1958) tarafindan yapılmıştır. Daha sonrasında Balassa (1965), “Açıklanmış Karşılaştırmalı Üstünlükler” yaklaşımını ile karşılaştırmalı üstünlüğü tespit etmek amacıyla endeks geliştirmiştir.

Batra ve Khan (2005) tarafindan 2000 ve 2003 döneminde Hindistan ve Çin'in sektörleri ve ürünleri için rekabet gücü analizi yapılmıştır. Çin ve Hindistan'ın tarımsal ürünlerinde rekabet gücüne sahip olduğu saptanmıştır. Hindistan pamuk, demir ve çelik, kimyasallar, giyim aksesuar sektörlerinde rekabet gücü olduğu saptanmıştır.

Şimşek ve Seymen (2007), 1993-2005 y1lları arasında Türkiye'nin Avrupa Birliği karşısındaki rekabet gücünü “Açıklanmış Karşılıklı Üstünlükler Endeksi” ile incelemiştir. Çalışmada teknoloji sınıflandırmasına göre analiz yapılmış olup Türkiye'nin Ar-Ge yoğun mallarda rekabet dezavantajının olduğu, ham madde ve emek yoğun mallarda rekabet gücüne sahip olduğu, sermaye yoğun mallarda ise nispi olarak rekabet avantaji olduğu saptanmıştır.

Seymen ve Gümüştekin (2012), 2010 yllı için yapmış oldukları çalışmada Türkiye'nin Avrupa Birliği pazarına olan Ar-Ge yoğun mallar farklı rekabet gücü endeksleri ile analiz etmişlerdir. 2010 yllında Avrupa Birliği’ne yapılan Ar-Ge yoğun mal ihracatına bakıldığında ürün düzeyinde en çok "ilaçlar" ve "radyo, TV ekipmanı ve cihazları" grubu ihraç edilirken en fazla "ilaçlar" grubu ithal edilmiştir. Türkiye Ar-Ge yoğun sektörler ana sektör olarak rekabet gücüne sahip olmamasina rağmen rekabet gücüne sahip ürünlerin olduğu saptanmıştır.

Ünlü (2018) yaptığ1 çalışmada 1996-2017 döneminde Türkiye'nin imalat sektörlerinin ihracatında BRICS ülkelerine karşı rekabet güçlerini “Açılanmış Karşılaştırmalı Üstünlükler Endeksi”ni kullanarak karşılaştırmıştır. Çalışmada Türkiye'nin BRICS ülkeleri karşısında çoğunlukla düşük ve orta teknolojili mallarda rekabet gücüne sahip olduğu saptanmıştır. Türkiye düşük ve orta teknoloji yoğun mallarda, Çin ise yüksek teknoloji yoğun mallarda BRICS ülkelerine yapılan ticarette en yüksek rekabet gücüne sahip ülke olmuştur. 
Çelik (2019), Türkiye ve BRICS ülkelerinin 1995-2017 yılları için emek yoğun mallarının rekabet gücü araştırlmıştır. "Açıklanmış Karşılaştırmalı Üstünlükler" endeksine göre Çin, Türkiye ve Hindistan emek yoğun mallarda rekabet gücüne sahiptir ancak rekabet güçleri yıllar itibarıyla azalmaktadır. Sermaye yoğun mallarda Brezilya, Rusya ve Türkiye düşük rekabet gücüne sahiptir. Türkiye, Ar-Ge yoğun mal ihracatında BRICS ülkeleri içerisinde en düşük rekabet gücü endeksine sahip ülke olup rekabet dezavantajina sahiptir.

Türkiye İhracatçılar Meclisi'nin 2019 yllında yayınlanan "Yeni Vizyon Yeni Yol Haritasi İhracat 2019" Raporunda 16 sektörün 2000, 2010 ve 2017 yıllarındaki “Açılanmış Üstünlükler Endeksi” hesaplanmıştır. Rapor'a göre "Tekstil ve giyim", "Minarellar", "Gıda ürünleri”, "Deri ve deri mamulleri” rekabet gücü zamanla azalmakta olup "Makineler ve elektrikli makine ve cihazlar", "Kimyasallar", "Madenler" sektörlerin rekabet gücü artmıştır.

Fidan (2020)'n yapmıs olduğu 2001-2018 dönemini kapsayan rekabet gücü analizinde Türkiye'de Demir-Çelik endüstrisi ele alınmıştır. Çalışmada "Açıklanmış Karşılaşıırmalı Üstünlükler" ve "Vollrath Endeks”leri kullanılmışır. Bu iki endekse göre Türkiye demir-çelik endüstrisinde rekabet gücüne sahiptir. Türkiye, "Açıklanmış Karşılaştırmalı Üstünlükler" endeksine göre Fransa ve Hollanda'ya karşı rekabet üstünlügüne sahip iken "Vollrath Endeksi”ne göre Polonya, Fransa, Çek Cumhuriyeti, Hollanda, Avusturya, Almanya'ya karşı rekabet gücü vardır.

Emikönel (2020), Çin'in “Elektrikli makine ve ekipman” sektörünün “Açılanmış Karşılaştırmalı Üstünlükler Endeksi", "Göreli İhracat Avantaj Endeksi”, "Göreli İthalat Avantaj Endeksi” ve "Göreli Ticaret Endeks"i ile rekabet gücü analiz edilmiştir. Çalışmanın analiz sonuçlarına göre Çin'in "Elektrikli makine ve ekipman" sektörünün dünya pazarındaki rekabet gücü oldukça yüksektir.

\section{Türkiye'de Elektrikli Makine ve Cihaz İmalatı Sektörlerine Ait Açıklanmış Karşılaştırmalı Üstünlükler Endeks Değerleri}

"Başka yerde sınıflandırılmamış elektrikli makine ve cihazlar" sektörü "Elektrik motorları, transformatörler ve jeneratörler"; "Elektrik dağıtım ve kontrol cihazları"; "İletkenler ve kablolar, aydınlatma ekipmanları", "Elektrikli ev aletleri "olmak üzere gruplara ayrilmaktadır. "Elektrik motorları, jeneratörler ve transformatörlerin imalatı" sektörlerinden STIC Rev.3 7161 kodlu "37,5 W gücü aşmayan elektrik motorlar1; 7162 kodlu "37,5 W gücü aşmayan doğrusal akım (DC) motor ve jeneratörleri”; 71631 kodlu "37,5 W gücü aşmayan alternatif akım motorları"; 71632 kodlu "alternatör akımlı jeneratörler"; 7164 kodlu "rotatif elektrikli konvertörler"; 71651 kodlu "elektrojen grupları"; 71652 kodlu "diğer elektrojen gruplarr"; 7169 kodlu "Elektrik motor- jeneratör, elektrojen grupları aksam ve parçaları"; 77111 kodlu "Sıv1 dielektrik transformatörler"; 77119 kodlu "Diğer elektrikli transformatörler"; 77121 kodlu "Statik konvertörler"; 77123 kodlu "Deşarj tüpleri, ampulleri için balastlar"; 77125 kodlu "Diğer endüktörler"; 77129 kodlu "Transformatör, konvertör, bobin, selflerin aksam-parçaları" alt sektörlerinin "Açıklanmış Karşılaştırmalı Üstünlükler Endeksi” ile rekabet gücü hesaplanmıștır. Bu sektörlerin içerisinde endeks değeri 1'den büyük olan ve rekabet gücüne sahip sektörler ve 2000-2019 yllları arasındaki seyri Tablo 3'te yer almaktadır.

Tablo 3. Elektrik Motorlar, Jeneratörler ve Transformatörlerin İmalatı Sektörleri İcerisinde Rekabet Gücüne Sabip Olan Sektörler

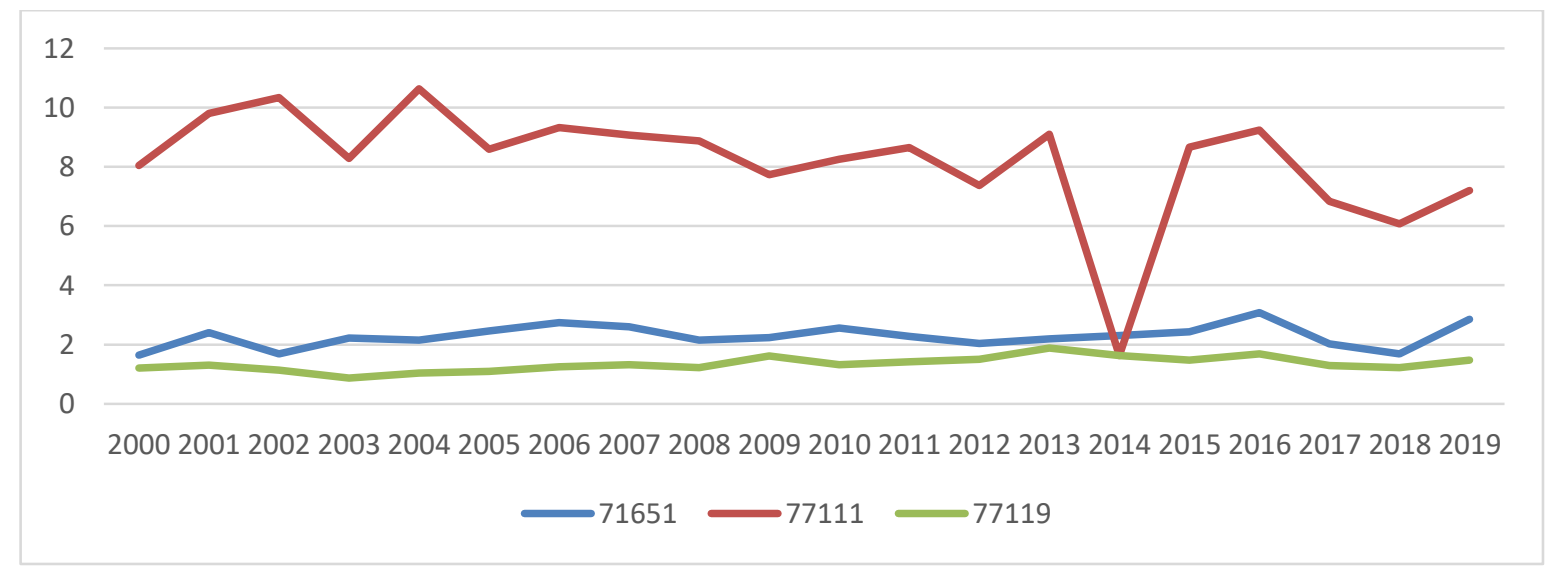

Kaynak: TÜIK ve UN Comtrade veri tabanından elde edilen verilerle hesaplanmıştır. 
Tablo 3’te en yüksek “Açıklanmış Karşlaştırmalı Üstünlükler Endeks” değeri 77111 kodlu "Sıvı dielektrik transformatörler" sektörüne aittir. Endeks değerleri en yüksek diğer sektörler 71651 kodlu "Elektrojen grupları" ve 77119 kodlu "Diğer elektrikli transformatörler" sektörleridir.

"Elektrik dağıtım ve kontrol cihazları imalatı" sektörleri içerisinde STIC Rev.3 77241 kodlu gerilimi 1000 voltu geçen sigortalar; 77242 kodlu " 72,5 kv'dan daha düşük voltaj için otomatik devre kesiciler"; 77243 kodlu "72,5 kv'a eşit veya daha büyük otomatik devre kesiciler"; 77244 kodlu "Devre ayırıcılar, yük ayırıcılar (açma-kapama şalterleri)"; 77245 kodlu "Yıldırım önleyiciler, gerilim sınırlayıcılar ve dalga bastırıcılar"; 77249 kodlu "Diğer voltaj teçhizatı"; 77251 kodlu "Gerilimi 1000 v’tan düşük eriyen iletkenli sigortalar;" 77252 kodlu "Otomatik devre kesiciler (disjonktörler); 77253 kodlu "Elektrik devrelerinin korunmasına yönelik diğer teçhizatlar"; 77254 kodlu "Röleler"; 77255 kodlu "Diğer anahtarlar (komütatörler, enterüptörler, starterler vb)"; 77257 kodlu "Ampul duylarr"; 77258 kodlu "Soketler, fişler ve prizler"; 77259 kodlu "Diğer elektrik devresi teçhizatı"; 77261 kodlu "1000 volta eşit veya düşük kontrol-dağıtım tabloları"; 77262 kodlu "Sayısal kumanda panoları"; 77281 kodlu "Kumanda panolarına tablo, konsol, kabin vb. teçhiz edilmiş"; 77282 kodlu "Elektrik devresi teçhizatı aksam-parçaları" sektörlerin içerisinde endeks değeri 1'den büyük olan ve rekabet gücüne sahip sektörler ve 2000-2019 ylları arasındaki seyri Tablo 4'te yer almaktadır.

Tablo 4. Elektrik. Dağttım ve Kontrol Cihazlar İmalatı Sektörleri Ị̇erisinde Rekabet Gücüne Sabip Olan Sektörler

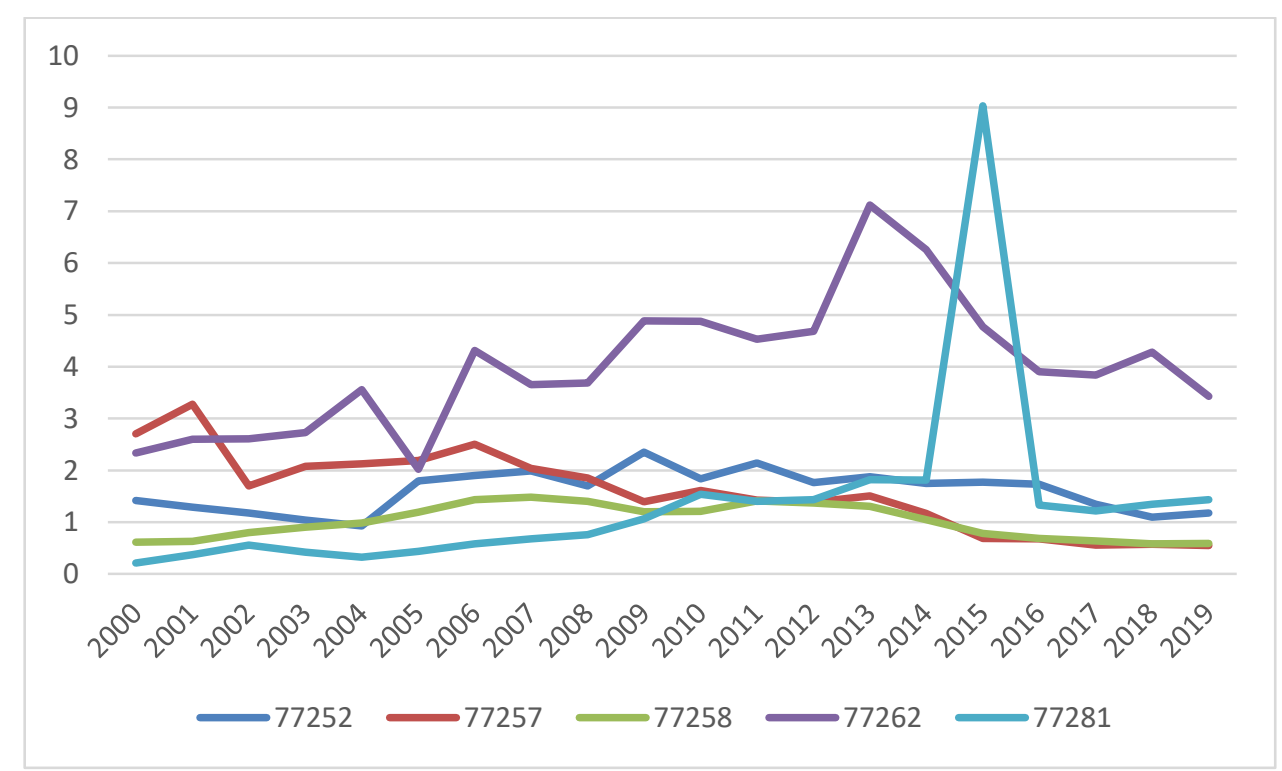

Kaynak: TÜIK ve UN Comtrade veri tabanından elde edilen verilerle hesaplanmıştır.

Tablo 4’te en yüksek “Açıklanmış Karşılaştırmalı Üstünlük Endeks” değerine sahip olan sektör 77262 kodlu "Sayısal kumanda panoları sektörü olmuştur. Bu alt sektörlerden rekabet gücü olan diğer sektörler 77258 kodlu "Soketler, fişler ve prizler, 77252 kodlu "Otomatik devre kesiciler (disjonktörler)", 77257 kodlu "Ampul duyları", 77281 kodlu "Kumanda panolarına tablo, konsol, kabin vb. teçhiz edilmiş" mal üreten sektörler olmuştur.

“Akümülatör, birincil pil ve birincil pil imalatı" sektörleri içerisinde STIC Rev.3 77811 kodlu "Primer elektrik pilleri ve bataryaları"; 77812 kodlu "Elektrik akümülatörleri (depolama bataryaları)"; 77817 kodlu "Primer elektrik pilleri/bataryaları aksam ve parçaları" ve 77819 kodlu "Akümülatör aksam ve parçaları, seperatörler” sektörleri içerisinde rekabet gücüne sahip sektör Tablo 5’te gösterilmiştir. 
Tablo 5. Akümülatör, Birincil Pil ve Birincil Pil İmalatı

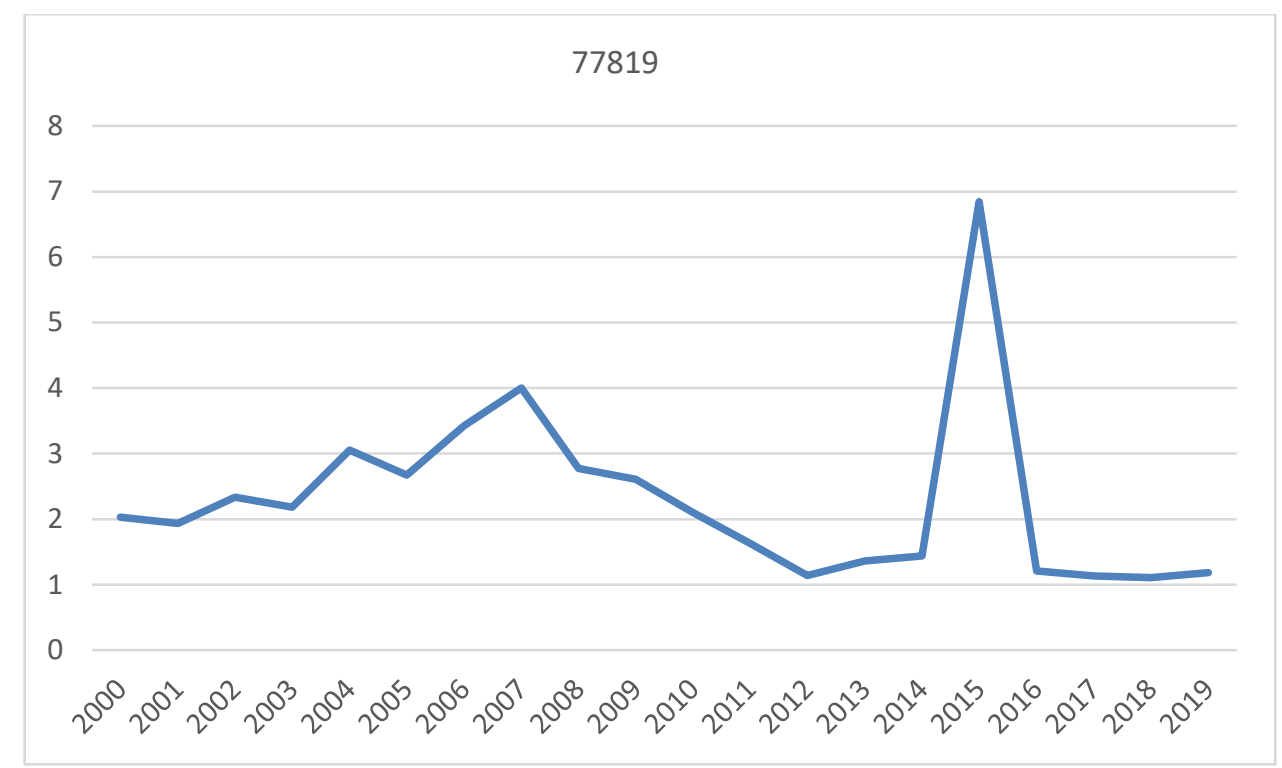

Kaynak: TÜIK ve UN Comtrade veri tabanından elde edilen verilerle hesaplanmıştır.

Tablo 5'te gösterildiği üzere 77819 kodlu "Akümülatör aksam ve parçaları, seperatörler" sektörü rekabet gücüne sahip olmakla birlikte 2000-2019 arası dönemde 1'in altına düşmemiştir.

"Elektrikli ev aletleri ve beyaz eşya" sektörü içerisinde bulunan STIC Rev.3 7751 kodlu "Kapasitesi $10 \mathrm{~kg}$ eşit veya daha az olan çamaşır ve kurutma makinesi"; 7752 kodlu "Buzdolabı ve dondurucular"; 7753 kodlu "Evlerde kullanılan bulaşık yıkama makinaları"; 7754 kodlu "Elektrik motorlu traş makineleri, saç kesme ve hayvan kırkma makinesi; 7757 kodlu " $\mathrm{Ev}$ işleri için elektromekanik-elektrik motorlu cihazlar ve 7758 kodlu "Başka yerde sınıflanmamış elektrotermik cihazlar" sektörlerinden "Açıklanmış Karşılaştırmalı Üstünlükler Endeksi”ne göre rekabet gücü olan sektörlerin 2000-2019 y1lları arasındaki seyri Tablo 6'da gösterilmiştir.

Tablo 6. Elektrikli Ev Aletleri ve Beyaz Essya Sektörü İcerisinde Rekabet Gücüne Sabip Olan Sektörler

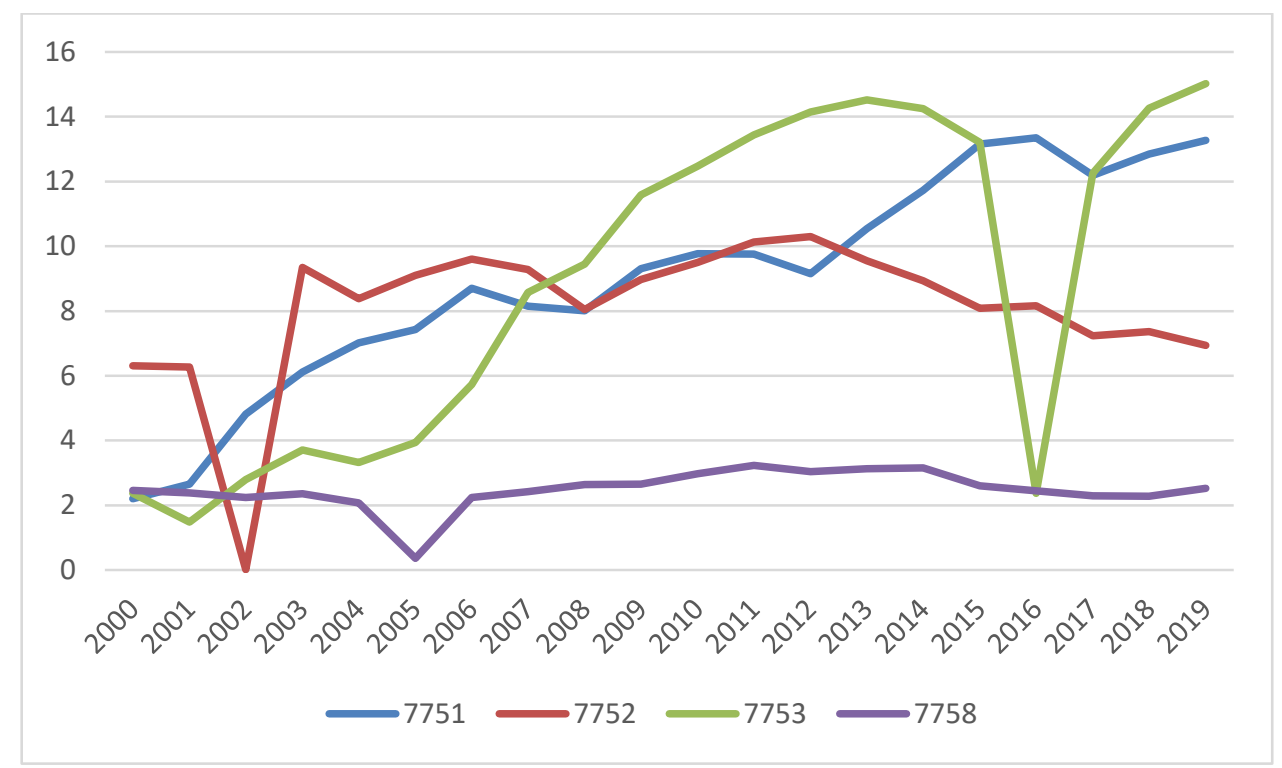

Kaynak: TÜIKK ve UN Comtrade veri tabanından elde edilen verilerle hesaplanmıştır.

Özellikle 7751 kodlu "Kapasitesi $10 \mathrm{~kg}$ eşit veya daha az olan çamaşır ve kurutma makinesi" sektörü ve 7753 kodlu "Evlerde kullanılan bulaşık yıkama makinesi" sektörleri dünya karşısında yüksek rekabet gücüne sahiptir. 7751 kodlu "Kapasitesi $10 \mathrm{~kg}$ eşit veya daha az olan çamaşır ve kurutma makinesi" sektörü endeks değeri 2000-2019 yllları arasında yükselme trendi göstermektedir. 7753 kodlu "Evlerde 
kullanılan bulaşık yıkama makineleri” özellikle 2015 yılına kadar yükseliş göstermiştir. 2016 yılında sert bir düşüş gerçekleşse de 2017-2019 arası dönemde tekrar yükselme eğilimine girmiştir.

"İzole tel ve kablo imalatı" sektörleri içerisinde yer alan STIC Rev.3 77311 kodlu "Bobin teli; 77312 kodlu "Koaksiyel kablo ve diğer koaksiyel elektrik iletkenler"; 77314 kodlu 80 volt'u aşmayan voltajlı elektrik iletkenleri"; 77315 kodlu " 80 V'u aşan ve 1000 V'u aşmayan bir voltajl elektrik iletkenleri”"; 77317 kodlu "1000 V'u aşan voltaj için elektrik iletkenleri"; 77318 kodlu "Fiber optik kablolar" alt sektörlerinde rekabet gücü yüksek sektörlerin 2000-2019 yılları arasindaki durumu Tablo 7'de gösterilmiştir.

Tablo 7. İzole Tel ve Kablo Imalat Sektörleri Ị̇erisinde Rekabet Gücüne Sabip Olan Sektörler

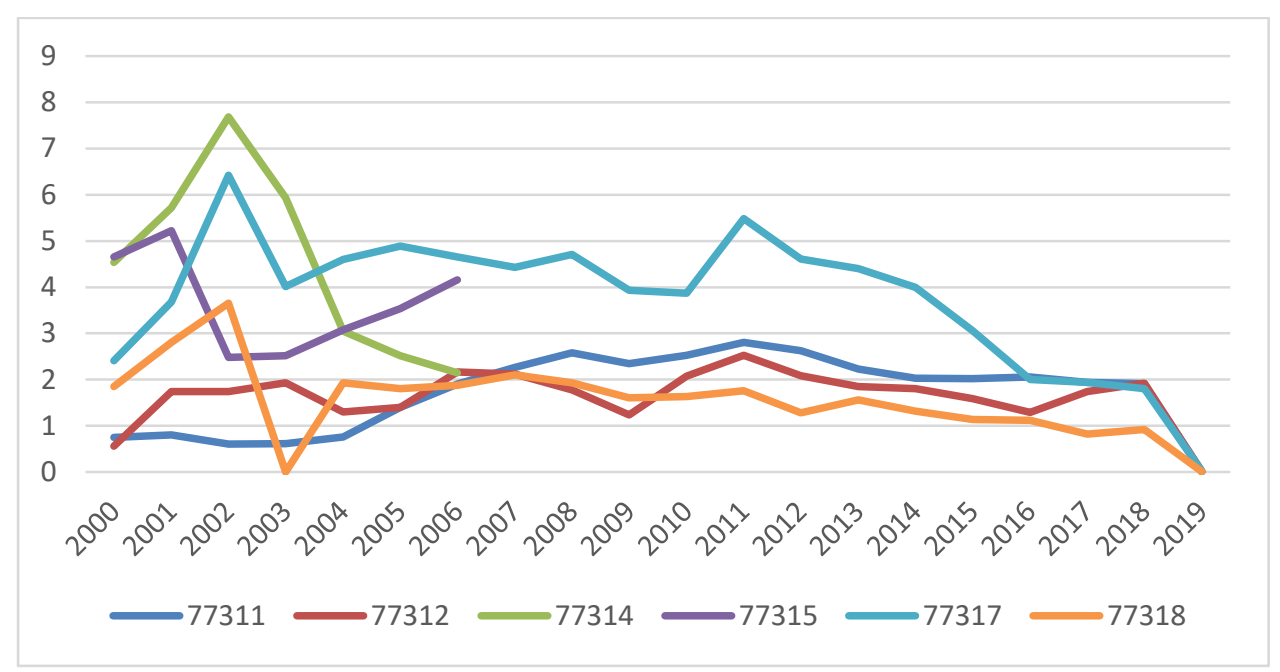

Kaynak: TÜIK ve UN Comtrade veri tabanından elde edilen verilerle hesaplanmıştır.

77317 kodlu "1000 V'u aşan voltaj için diğer elektrik iletkenleri” sektörünün rekabet gücü yüksek olup 2004-2016 yllar1 arasında bu sektördeki en rekabetçi sektör olmuştur. 77314 kodlu "80 volt'u aşmayan voltaj için elektrik iletkenleri" alt sektörü 2000-2004 yılları arasında rekabet gücü yüksek iken 2004 ylından sonra rekabet gücü azalmıştır.

"Elektrik lambaları ve aydınlatma teçhizatı imalatı" sektörü STIC Rev.3 77821 kodlu "Famanlı ampuller; 77822 kodlu "Deşarj ampul-tüpleri; 77823 kodlu "Monoblok far üniteleri”; 77824 kodlu "Mor ötesi/kızıl ötesi ışınlı ampuller; ark lambaları"; 77829 kodlu "Kızma, deşarj esaslı elektrik ampul vb aksamparçaları"; 81311 kodlu "Avizeler, duvar, tavan için aydınlatma cihazları"; 81312 kodlu "kendi elektrik kaynağı ile çalışan elektrik lambası"; 81313 kodlu "Masa, sıra, yatak odası, döşemeye konan ayaklı elektrik lambası", 81315 kodlu "Diğer elektrik lambaları ve aydınlatma cihazları"; 8132 kodlu "Reklam lambaları, ışıklı tabelalar, ışıklı isim plakaları vb"; 8138 kodlu "Kendi elektrik kaynağı ile çalışan elektrik lambalarının aksam-parçası"; 81399 kodlu "Aydınlatma cihazları diğer aksam parçaları"; 88112 kodlu "Flaş 1şı̆̆ meydana getiren tertibat"; 89841 kodlu "eni 4 mm'yi geçen ve 6,5 mm'yi geçmeyen manyetik bantlar" alt sektörler içerisinde rekabet gücüne sahip olan 8132 ve 81311 alt sektörlerin 2000-2019 y1llar1 arasındaki seyri aşağıdaki Tablo 8'de yer almaktadır. 
Tablo 8. Elektrik Lambalar ve Aydinlatma Teģbizatı İmalatı Sektörü Iscerisinde Rekabet Gücüne Sabip Olan Sektörler

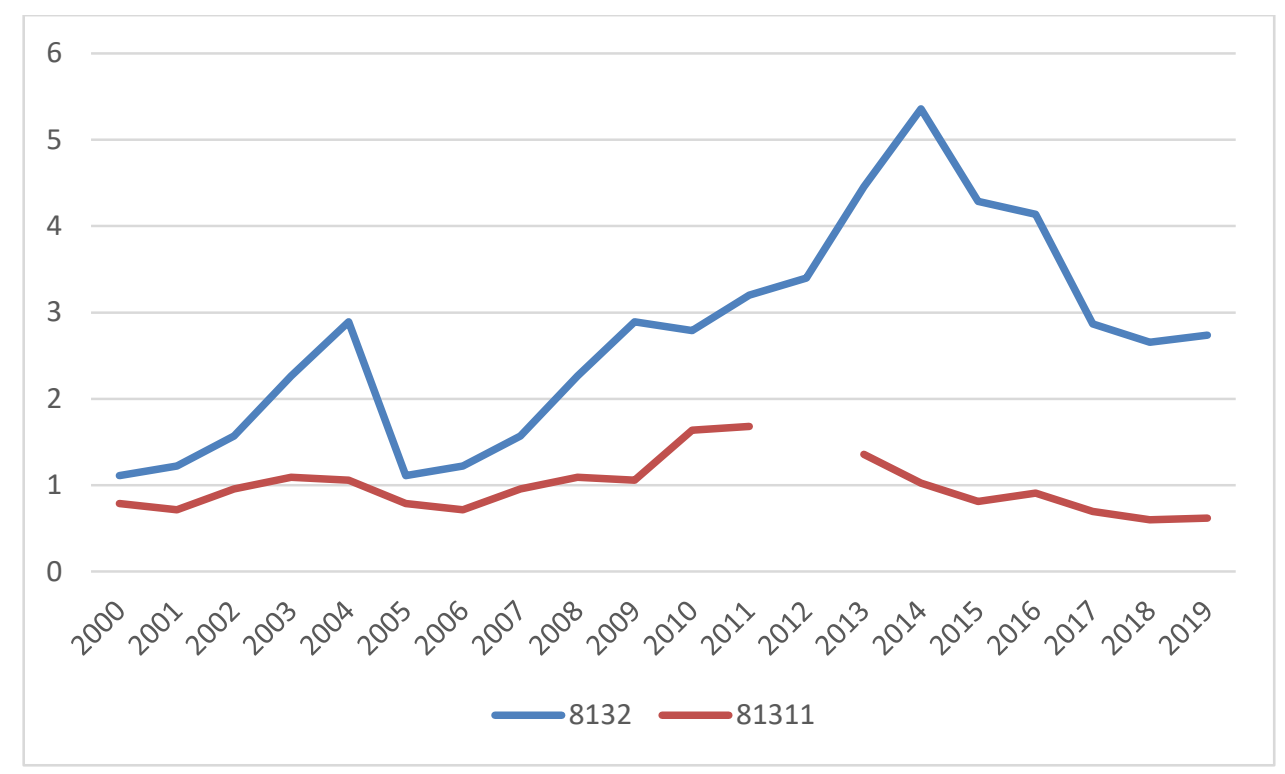

Kaynak: TÜIKK ve UN Comtrade veri tabanından elde edilen verilerle hesaplanmıştır.

Bu alanda rekabet gücü olan iki sektör vardır. Bunlardan birincisi 8132 kodlu "Reklam lambaları, 1şıklı tabelalar, ışıklı isim plakaları vb. sektörü ve 81311 kodlu "Avizeler, duvar, tavan için aydınlatma cihazları sektörleridir.

\section{Tartışma, Sonuç ve Öneriler}

"Başka yerde sınıflandırılmamış elektrikli makine ve cihazlar" sektörünün piyasalara arz ettikleri ürünler tüm sektörler tarafından nihai mal, ara girdi ya da yatırım malı olarak talep edilmektedir. Bu sektör içerisindeki "Elektrikli motor ve jeneratör, transformatör", "İzole edilmiş tel ve kablo", "Pil batarya ve akümülatör", "Elektrik dağıtım ve kontrol cihazları", "Elektrik lambası ve aydınlatma cihazlar"1, "Elektrikli ev aletleri imalatı" gibi alt sektörlerden dünya piyasalarında rekabet gücüne sahip sektörlerin tespit edilmesi, bu sektörlerin dış bağımlılığın azaltılması, Ar-ge faaliyetlerinin ve yatıımların desteklenmesi açısından önemlidir. Politikalarında elektrik sektörünü önceleyen Güney Kore, Malezya, ABD, Çin, Singapur ülke örnekleri göz önüne alındığında bu sektörün gelişmesine yönelik adımların atılması gerekliliği ortaya çıkmaktadır.

Türkiye'de "Elektrikli ev aletleri ve beyaz eşya" sektörünün başarısı rekabet gücünün yüksek olması sonucunu beraberinde getirmiştir. Beyaz eşya imalatı sektörü; teknolojisini kendisi üretebilen, yenilikçi, yüksek araştırma ve geliştirme faaliyeti yürüten, ürün çeşitliliği yüksek bir sektör haline gelmiştir. Bazı sektörler dev bütçeli sermaye yatırımları, uluslararası işbirlikleri, teknolojik anlamda sinerji ortamı yaratacak olan kümelenmeleri gerektirmektedir. Rekabet gücüne sahip olan alt sektörlerin tespit edilerek desteklenmesi katma değer ve istihdamı artıracak ve ekonomik büyümeyi destekleyecektir.

Bu çalışmada 2000-2019 yılları arasında ISIC Rev. 331 kodlu "Başka yerde sınıflandırılmamıs elektrikli makine ve cihazlar" sektörünün alt sektörlerinin rekabet gücü "Açıklanmış Karşılaştırmalı Üstünlükler Endeksi” ile analiz edilmiştir. "Elektrik motorlanı, jeneratörler ve transformatörlerin imalatı" sektörlerinden 77111 kodlu "Siv1 dielektrik transformatörler", 71651 kodlu "Elektrojen gruplar1", 77119 kodlu "Diğer elektrikli transformatörler" sektörü uluslararası rekabet gücüne sahiptir. "Elektrik dağıttmm ve kontrol cihazları imalatı" sektörleri içerisinde 77262 kodlu "1000 V'u aşan voltaj için sayısal kumanda panoları", 77258 kodlu "Soketler, fişler ve prizler"; 77252 kodlu "Otomatik devre kesiciler (disjonktörler)"; 77257 kodlu "Ampul duyları", 77281 kodlu "Kumanda panolarına tablo, konsol, kabin vb. teçhiz edilmiş" grubunda mal üreten sektörler rekabet gücüne sahiptir. "Akümülatör, birincil pil ve birincil pil imalat" sektörleri içerisinde 2015 yılına kadar 77819 kodlu "Akümülatör aksam ve parçaları" sektörü uluslararası rekabete sahiptir. "Elektrikli ev aletleri ve beyaz eşya" sektörü içerisinde 7751 kodlu "Kapasitesi $10 \mathrm{~kg}$ eşit veya daha az olan çamaşır ve kurutma makinesi", 7752 kodlu "Buzdolab1 ve dondurucular", 7753 kodlu "Evlerde kullanılan bulaşık yıkama makinaları", 7758 kodlu "Başka yerde 
sınıflanmamış elektrotermik cihazları" rekabet gücüne sahiptir. "İzole tel ve kablo imalatı" sektörleri içerisinde yer alan 77311 "Bobin tel"i, 77312 "Koaksiyel kablo ve diğer koaksiyel elektrik iletkenler", 77317 kodlu "1000 V'u aşan voltaj için elektrik iletkenleri", 77314 kodlu "80 volt'u aşmayan voltajlı elektrik iletkenleri”, 77315 "80 V'u aşan ve 1000 V'u aşmayan bir voltajl elektrik iletkenleri”, 77317 kodlu "1000 V'u aşan voltaj için elektrik iletkenleri”, 77318 "Fiber optik kablolar sektörü" rekabet gücüne sahiptir. "Elektrik lambaları ve aydınlatma teçhizat imalatı" sektörü içerisinde 8132 kodlu "Reklam lambaları, 1şıklı tabelalar, 1şıklı isim plakaları vb." sektörü ve 81311 kodlu "Avizeler, duvar, tavan için aydınlatma cihazları” sektörlerinin rekabet gücüne sahip olduğu tespit edilmiştir.

\section{Etik Beyan}

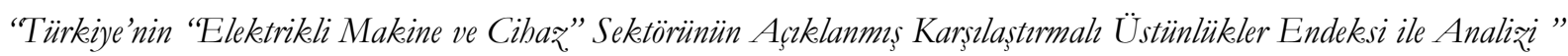
başlıklı çalışmanın yazım sürecinde bilimsel kurallara, etik ve alıntı kurallarına uyulmuş; toplanan veriler üzerinde herhangi bir tahrifat yapılmamış ve bu çalışma herhangi başka bir akademik yayın ortamına değerlendirme için gönderilmemiştir. Bu araştırma doküman incelemesine dayalı olarak yapıldığından etik kurul kararı zorunluluğu bulunmamaktadır.

\section{Kaynakça}

Aiginger, K. (1998). A framework for evaluating the dynamic competitiveness of countries. Structural Change and Economic Dynamics, 9(2), 159-188.

Balassa, B. (1965). Trade liberalisation and revealed comparative advantage. The Manchester School of Economics and Social Science, 33, 99-123.

Batra, A. ve Zeba, K. (2005). Revealed comparative advantage: an analysis for india and china. Indian Council for Research on International Economic Relations, 168: 1-85.

Çelik, A. (2019). Ülkelerin faktör yoğunlukları bakımından rekabet gücünün ölçümü: BRICS-T özelinde karşılaştırmalı bir analiz. Journal of Yaşar University, 14(55), 339-357.

Çivi, E., Erol, İ., İnanl, T. ve Erol, E.D. (2008). Uluslararası rekabet gücüne farklı bakışlar. Ekonomik ve Sosyal Arastrmalar Dergisi, 4(1). 1-22.

Emikönel, M.(2020). Measuring Competitiveness in Chinese Electrical Macbinery and Equipment Industry. Editura Universitara \&ADI Publication.

European Commission (2003). European competitiveness report 2003. 1299 Commission Staff Working Document, Luxembourg. Erişim Adresi:https: //ec.europa.eu/growth/content/european-competitiveness-report2003-0 nn.

Fagerberg, J. (1988). International competitiveness. The economic journal, 98 (391), 355-374.

Fidan, H. (2020). Demir veya çelikten eşya ticaretinde türkiye'nin karşılaştırmalı üstünlüğü ve rekabet gücü. Mehmet Akif Ersoy Üniversitesi Uygulamal Bilimler Dergisi, 4(1), 1-21.

Hinloopen, J.ve Marrewijk, C. V. (2000). On the empirical distribution of the Balassa index. Review of World Economics, $137(1), 1-35$.

IMD-International Institute for Management Development (2003). World competitiveness yearbook 2003. Lausanne, Switzerland.

Liesner, H. (1958). The European common market and British Industry. The Economic Journal, 68(270), 302-311.

Porter, M. E. (1990). The Competitive Advantage of Nations, New York: The Free Press.

Rusu, V.D. ve Roman, A. (2018). An empirical analysis of factors affecting competitiveness of C.E.E. countries. Economic Research-Ekonomska Istraživanja, 31(1)., 2044-2059.

Scott, B.R. and Lodge, G.C. (1985). US competitiveness in the world economy. Boston: Harvard Business School Press. 3.

Seymen, D. ve Gümüştekin, B. (2012). R\&D intensive goods trade and competitiveness of Turkey in the European Union market. Turkish Economic Association Discussion Paper 2012/24.

Şimşek, N., Seymen, D. ve Utkulu, U. (2007). Turkey's competitiveness in the EU Market: A Comparison of Different Trade Measures, European Trade Study Group (ETSG) 9th Annual Conference 2007. Atina.

Türkiye Cumhuriyeti Ekonomi Bakanlığı, (2016). Elektrikli makineler ve kablolar sektör raporu. Erişim Adresi: http://www.iso.org.tr/Sites/1/upload/files/elektriklimakine-333.pdf.

Türkiye İhracatçılar Meclisi, İhracat 2019 Raporu: Yeni Vizyon, Yeni Yol Haritas1, https://www.immib.org.tr/files/kio/temp/Yeni $\% 20$ Vizyon $\% 20 \mathrm{Yeni} \% 20 \mathrm{Yol} \% 20 \mathrm{Haritas} \% \mathrm{C} 4 \% \mathrm{~B} 1 \% 20 \% \mathrm{C}$ 4\%B0hracat\%202019\%20Raporu.pdf (Erișim tarihi:28.12.2020)

Ünlü, F. (2018). İmalat sanayinin rekabet gücündeki değişimin teknoloji yoğunluğuna göre ölçülmesi: Türkiye ve BRICS ülkeleri örneği. Akademike Arasttrmalar ve Callsmalar Dergisi, 10(19), 422-441.

https://ticaret.gov.tr/data/5b87000813b8761450e18d7b/Elektrikli Makine ve Kablolar.pdf

Walsh, V. (1994). The technology and the economy- the key relationships : (Organization for economic co-operation and development,Paris,1992). Researcb Policy, 473-475. Doi: https://doi.org/10.1016/0048-7333(94)90011-6. 


\section{EXTENDED ABSTRACT}

The aim of this study is to analyze Turkey's ISIC Rev. 3 31-coded "Electrical machinery and equipment, not elsewhere classified" sector between 2000-2009 against world's competitors applying "Revealed Comparative Advantage Index". The electrical equipment manufacturing industry provides the production of high value-added products. It converts electricity power which is the source of energy to useful things for people. The sector has a wide range of products and produces intermediate input, investment goods and final consumer goods. The sector carries out the production of electrical energy products that distributes and uses electricity. The product groups include electrical home appliances, signaling equipment, electrical signaling and lighting equipment. In the "Electrical Equipment Manufacturing" industry, technology infrastructure and the ability to develop new technology are decisive in terms of international competitiveness. In this sector, countries such as Japan, South Korea, Taiwan, Singapore, France, Germany, the United States and Sweden are competitive countries. Manufacturing sub-sectors except for the white goods industry "Electrical equipment manufacturing" in Turkey are quite limited. White goods sector in Turkey has its own large production technology. Foreign dependency continues in other sub-sectors and there is a significant foreign capital investment. Innovation and product variety increases in the electrical small home appliances and white goods sector and a high level of R\&D expenditure are made in this very sector. Electric equipment manufacturing sector electric motors, transformers and generators electrical distribution and control devices; conductors and cables are divided into groups as lighting equipment, electrical appliances, white goods and small home appliances. Turkey has faced intense competition with the Customs Union and the variety and quality of products has increased as a result of competition with European Union member countries. It has become a country that transfers technology in this sector by developing new designs and technologies in the electrical appliances industry. The main purpose of providing international competitiveness is to increase welfare and increase the standard of living. Countries can catch up with competitors in product production and distribution by focusing on their unique capabilities. In determining the competitiveness of a country, many indicators such as production, employment, foreign trade balance, market share in international markets should be used together. Different indices have been developed to measure international competitiveness. One of the indices frequently used in the literature is "Balassa Index". Bela Balassa (1965) named the comparative advantage measured by countries' export data as "Revealed Comparative Advantages". If the index value is greater than 1 , it means that the relevant sector has competitive power. According to "Revealed Comparative Advantage Index" STIV Rev.3, it was identified that following subsectors have competitiveness power: 77111 code liquid dielectric transformers; 71651 code electric generating sets with compression-ignition internal combustion piston engines (diesel or semi-diesel engines), 77119 code other electrical transformers, 77262 code...for a voltage exceeding; 77258 code plugs and sockets; 77252 code automatic circuit-breakers; 77257 lamp- holders; 77281 code boards, panels, consoles, desks, cabinets and other bases for the goods of subgroup 772.6, not equipped with their apparatus; 77819 code parts of electric accumulators; 7751 code household-type laundry equipment, n.e.s.; whether or not electrical; 7752 code household-type refrigerators and food freezers (electrical and other); 7753 code dishwashing machines of the household type; 7758 code electro thermic appliances, n.e.s.; 77317 code other electric conductors, for a voltage exceeding 1000V; 77314 code other electric conductors, for a voltage not exceeding $80 \mathrm{~V}$ ); 8132 code illuminated signs, illuminated name-plates and the like and 81311 code chandeliers and other electric ceiling and wall lighting fittings (excluding those of a kind used for lighting public open spaces or thoroughfares). Electrical equipment manufacturing industry, which is medium high-tech sector, is one of Turkey's most important sectors. Forward and reverse linkage coefficient is high and is one of the key sectors of Turkey's economy. This means that it provides intensive input to other sectors and receives intensive input from other sectors as well. It has strong inter-industry links. It can be an indicator in terms of identifying sectors with high international competitiveness from the sub-sectors of the ISIC Rev.3 31 coded "Electrical Machinery and Equipment" manufacturing industry, encouraging investments in this field and providing more R\&D support to these sectors. Measuring international competitiveness is an important indicator in terms of revealing the position of a sector in the world market. It is impossible for any country to have a competitive advantage alone in the entire electrical equipment-manufacturing sector, electrical equipment manufacturing requires high budget investments, high research and development expenditures, qualified workforce and complex organizational structure. Therefore, this study determined the competitiveness of Turkey's "Electrical equipment manufacturing" sub-sectors. 